In R. Hurlemann \& V. Grinevich (Ed.), Behavioral Pharmacology of Neuropeptides: Oxytocin (pp.421-448). New York: Springer International Publishing AG, 2017

\title{
Oxytocin and human sensitive and protective parenting.
}

\author{
Marian J. Bakermans-Kranenburg \& Marinus H. van IJzendoorn'1
}

\begin{abstract}
In this chapter we review the evidence for the role of oxytocin in parenting, and discuss some crucial but outstanding questions. This is not meant to be a comprehensive review of all studies on oxytocin and parenting in general. Instead, special attention will be paid to a dimension of parenting that has been largely neglected in behavioral and neurobiological research on parental caregiving, namely protection. Parental protection has received considerable attention in animal research but, despite its evolutionary importance, not in studies on humans. It is argued that oxytocin may have specific significance for the protective dimension of parenting. The effects of exogenous oxytocin may be dependent not only on contextual factors, but also on personal characteristics, most notably gender, on endogenous levels of oxytocin, and on early childhood experiences. Examining the contextual, personal, hormonal, neural, genetic, and behavioral mechanisms of protective parenting in tandem is essential for the development of a comprehensive theory of protective parenting, and for the identification of "biomarkers" for insensitive and unprotective parenting that should be taken into account in preventive parenting interventions.
\end{abstract}

\section{Oxytocin in the Context of Sensitive and Protective Parenting}

Interest in oxytocin has increased rapidly in the past decades, both in scientific research and among the general public. Its role as a uterus-contracting hormone had been established in the 1950s, and subsequently the effects of oxytocin on sexual and reproductive behaviors were discovered, to be followed by its associations with a broad range of social behaviors, including trust and empathy (see $\mathrm{XX}$, chapter YY). Today, oxytocin is characterized on the internet mostly as the 'love hormone' or 'liquid trust'. Despite this popular but undeserved reputation its role in parenting remains crucial.

Correlational and experimental studies alike have examined oxytocin in relation to various aspects of parenting. Oxytocin facilitates parental caregiving and mother-infant bonding in humans

\footnotetext{
${ }^{1}$ Marian J. Bakermans-Kranenburg (corresponding author)

Center for Child \& Family Studies

Graduate School of Social and Behavioral Sciences

Leiden University, The Netherlands

email: bakermans@fsw.leidenuniv.nl

Marinus H. van IJzendoorn

Center for Child \& Family Studies

Graduate School of Social and Behavioral Sciences

Leiden University, The Netherlands

and

Center for Moral Socialization Studies

Erasmus University Rotterdam, The Netherlands

email: vanijzen@fsw.leidenuniv.nl
}

key words: oxytocin, parenting, protection, infant, attachment 
and various other species (Carter, 1998; Feldman \& Bakermans-Kranenburg, 2017; Insel, 2010). In rats, females avoid or attack pups, and show maternal behavior only after parturition. After OT injection, however, virgin females display all essential aspects of maternal behavior, including nest building and crouching over pups in a nursing posture (Fahrbach, Morrell \& Pfaff, 1984; Pedersen, Ascher, Monroe \& Prange, 1982). Conversely, the postpartum onset of maternal behavior is blocked by an OT receptor antagonist (Fahrbach, Morrell \& Pfaff, 1985). Similar effects are found in sheep: they show maternal behavior only after parturition or, alternatively, with experimentally increased OT levels (Kendrick, Da Costa, Broad, Ohkura, Guevara, Lévy et al., 1997; Keverne \& Kendrick, 1992). Surprisingly, OT knockout mice show relatively normal maternal behavior (Nishimori, Young, Guo, Wang, Insel \& Matzuk, 1996; Young, Winslow, Wang, Gingrich, Guo, Matzuk et al., 1997). Nevertheless OT might still be important for parenting in mice -- the explanation may be that vasopressin (AVP), which can cross-bind to OT receptors, fills the gap. Mice with a knockout of the OT receptor do show deficits in maternal behavior (Takayanagi, Yoshida, Bielsky, Ross, Kawamata, Onaka et al., 2005), so even these findings point to the crucial role of the oxytocin system.

In human parenting, oxytocin (from the Greek ỏ łúc tókos, meaning speedy delivery) has an important function during delivery and breastfeeding, but oxytocin has also been related to other parental behaviors. Three perspectives on how oxytocin affects general social behavior have been proposed: (i) via anxiety reduction, (ii) by increasing social salience, or (iii) through increasing reward sensitivity. Each of these mechanisms may also play a role in the specific domain of social behavior that comprises parenting. In this chapter we will discuss the evidence for the role of oxytocin in parenting, and indicate what outstanding questions remain to be answered. We do not aim to give a comprehensive review of all studies on oxytocin and parenting - several excellent reviews are available (e.g., Galbally, Lewis, Van IJzendoorn \& Permezel, 2011; Rilling, 2013; Swain, Kim, Spicer, Ho, Dayton, Elmadih et al., 2014) - but we will pay special attention to a dimension of parenting that is largely neglected in behavioral and neurobiological research on parental caregiving, namely protection. Parental protection has received considerable attention in animal research but, despite its evolutionary importance, not in studies on humans. That we highlight protective parenting in a chapter on the role of oxytocin in parenting is not trivial: We argue that oxytocin may have specific significance for the protective dimension of parenting.

\section{Parenting and Attachment}

Attachment theory is an influential theoretical framework guiding research in parenting and developmental science, and helpful for understanding the potential role and function of oxytocin in human parenting. In the most general definition of attachment, it is an inborn bias of human infants to seek proximity to a protective caregiver in times of stress, distress, illness, and other physical or psychological discomfort (Bowlby, 1969/1982). Human offspring would not be able to survive without the care of a stronger or more experienced conspecific who is able to regulate body temperature, food intake, and stress levels because young infants cannot take care of these basic physiological and psychological needs by themselves. The early environment of evolutionary adaptedness required the basic ability to show attachment behaviors and to become emotionally attached to a caregiver in order to survive and enhance inclusive fitness (Bowlby, 1969/1982).

Although all infants are born with the ability to become attached to a protective caregiver, they differ in the way in which this competence is expressed. Differences in attachment behaviors and relationships emerge in the course of the first few years of life as a consequence of childrearing experiences with parents and other caregivers. Infants tend to develop secure attachments in response to a sensitive and predictable social environment. The association between sensitive parenting and secure infant-parent attachment has been meta-analytically and experimentally supported (De Wolff \& Van IJzendoorn, 1997; Bakermans-Kranenburg, Van IJzendoorn, \& Juffer, 2003). In turn, secure infant-parent attachment is associated with better child socioemotional outcomes, including higher quality interpersonal relationships and lower externalizing and internalizing problems (Fearon, Bakermans-Kranenburg, Van IJzendoorn, Lapsley \& Roisman, 2010; Groh, Roisman, Van IJzendoorn, Bakermans-Kranenburg, \& Fearon, 2012; Groh, Fearon, Bakermans-Kranenburg, Van IJzendoorn, Steele \& Roisman, 2014). Although effect sizes for the associations between parental sensitivity, child 
attachment, and developmental outcomes are modest, they constitute some of the most thoroughly tested and replicated findings in the developmental literature.

\subsection{Sensitive parenting}

The importance of the quality of the early infant-parent attachment relationship for later child developmental outcomes necessarily has led to an avalanche of studies on predictors of secure attachment. The single most studied and well-validated predictor of the quality of attachment is parental sensitivity, understood as the parent's ability to (1) notice child signals, (2) interpret these signals correctly, and (3) respond to these signals promptly and appropriately (Ainsworth, Bell \& Stayton, 1974). These components of parental behavior refer to universally relevant aspects of caregiving, including proximity to the child (necessary for protection and meeting basic needs), contingent responding (promoting social and cognitive development), and appropriateness of parental interventions based on the child's responses rather than on a fixed list of specific parenting behaviors (Ainsworth, 1967).

Parental sensitivity is usually observed during parent-child interaction at home or in the lab, during free play or with some pressure put on the dyad, either with a task that is frustrating to the child, or with a competing demand for the parent, who as a result has to divide his or her attention between a task (e.g., completing a questionnaire) and the child. The improved predictive power of observed parental sensitivity in a competing-demand setting or in response to stress (Leerkes, Blankson, \& O'Brien, 2009); McElwain \& Booth-LaForce, 2006) may reflect the higher ecological validity of the setting --no parent is $24 / 7$ available with undivided attention to the whims of the child-as well as the child's more urgent need for sensitive parenting when it is in distress. However, for obvious reasons the stress during observations of parent-child interaction in laboratory or home settings has been limited to mildly stressful and non-threatening tasks. In reality, the source of distress may be acute danger, and in such situations the child needs not only emotional support from a sensitive caregiver, but also protection.

\subsection{Protective parenting}

Sensitive responsiveness has been operationalized in various ways, including dimensions such as emotional support, stimulation, and mutuality (DeWolff \& Van IJzendoorn, 1997). Conspicuously absent among these dimensions of parenting is the dimension of parental protection (BakermansKranenburg \& Van IJzendoorn, 2017). This is the more remarkable since in the environment of evolutionary adaptedness, genetic selection may have favored attachment behaviors just because they increased the likelihood of protection by increased infant-parent proximity (Simpson \& Belsky, 2008). This points to a strong parallel between infant attachment as proximity seeking to a protective caregiver, on the one hand, and parental protection of the infant on the other hand: the same dynamics and evolutionary roots may apply. Protection from predators is by far the most likely function of attachment behavior (Bowlby,1969/1989, p.226), for three reasons: an isolated individual is much more likely to be attacked than one that is in close proximity of a stronger conspecific, attachment behaviors are observed especially in those who are, because of their age or condition, most vulnerable to predators, and attachment behavior is elicited at high intensity in situations of alarm. The absence of parental protection perhaps demonstrates most convincingly that protection is a crucial aspect of human parenting. Neglect as the most clear-cut example of absent protection shows the highest prevalence of all categories of child maltreatment and has serious consequences for many domains of child development (Gilbert, Widom, Browne, Fergusson, Webb \& Janson, 2009). Physical abuse as the opposite of parental protection has its peaks in early childhood, when protection is most necessary.

In animals, protection of offspring is part and parcel of the task of new parents. Female chimpanzees with dependent infants keep their offspring close to them in the presence of males (Otali \& Gilchrist, 2006) and they do so for good reasons, for males show no mercy to infants that are not theirs. In rodents, attacking intruders and retrieving pups that move away from the litter are considered as indications of good parenting (Pedersen, Caldwell, Walker, Avers \& Mason, 1994). But human history is also fraught with attacks on vulnerable children and with infanticide. In studies carried out among the Ache Indians, a hunter-gatherer society in Paraguay, out-group tribe members constituted 
the single largest cause of child mortality (Hill \& Hurtado, 1996). Stranger anxiety, which begins to develop around the time that infants begin to crawl, is universal and may be an evolved mechanism facilitating caution towards strangers (Hahn-Holbrook, Holbrook \& Bering, 2010). Apart from attacks by strangers, disease and accidents have posed two other major risks to infant survival throughout human history. Parental protection was a matter of life and death (Hrdy, 1999).

Somewhere deep down, this is on parents' minds. Parents are preoccupied with potential threats during the postpartum period (Hahn-Holbrook, Holbrook \& Hasselton, 2011)Error!

Bookmark not defined.. Roughly $75 \%$ of parents of newborns report extraordinary levels of preoccupation with thoughts of potential harm to their children (Abramowitz, Schwartz \& Moore, 2003; Leckman, Mayes, Feldman, Evans, King \& Cohen, 1999). Even today, one of the foremost anxieties of parents is that their child will be abused or killed by strangers (Kantrowitz, 1997; Kidscape, 1993), although in reality homicide accounts for less than $1 \%$ of actual harm to children. The fear of attack by conspecifics thus seems to reflect a primordial parental worry. Male strangers are feared by both adults and infants (Navarrete, Olsson, Ho, Mendes, Thomsen \& Sidanius, 2009; Feinman, 1980; Skarin, 1977). This holds even if those infants' primary caregivers are male, countering the explanation that the aversion to males results from greater familiarity with females (Lamb, Hwang, A.M. Frodi \& M. Frodi, 1982).

The second threat to child survival, disease, is a serious threat indeed, given that $70 \%$ of deaths under 5 years of age are due to infectious diseases, with infancy standing out as the most vulnerable phase of development (UNICEF, 2013). We will return to parental avoidance of pathogens and unhealthy individuals to protect their children from disease later in this chapter (see paragraph 3.1.2). Accidents occur relatively frequently; the leading major cause of injury in modern times is falling from heights or furniture (Agran, Anderson, Winn, Trent, Walton-Haynes \& Thayer, 2003; Macgregor, 2003). Although such injuries are usually not fatal, the consequences can be serious. Parents must therefore be evolutionarily equipped to try and protect their children from disease, accidents, and stranger violence, particularly during infancy. It has been suggested that a special motivational system, the security motivation system, evolved to manage risks entailed by the possibility of events that are improbable but would have grave consequences (Woody \& Szechtman, 2011). The function of this system is to detect subtle or uncertain signs of potential threat, to collect further information about such potential dangers, and to generate precautionary behavior such as protective parenting that would buffer the effects once the threat becomes a reality. The system would be orchestrated via cortico-striato-thalamo-cortical circuits, and damage to or malfunctioning of the involved regions is predictive of impaired protective parenting behavior, at least in rodents (Maclean, 1990).

\subsection{Protection strategies: tend-and-befriend or tend-and-defend}

The little research of parental protection in response to cues of potential danger has mostly involved mothers (Hahn-Holbrook et al., 2011). Mothers may be expected to be more focused on protection of offspring than fathers, given human mothers' high investment in pregnancy, child birth, and breast-feeding. Fathers however do play a critical role in the protection of offspring, as evident from the two-fold increase in the likelihood of child death in traditional societies when the father is absent due to death or divorce (Hurtado \& Hill, 1992). These numbers may be mitigated in modern society, but they underscore the plausibility that fathers, not unlike mothers, have the innate tendency to protect their infants. But will they use similar strategies to protect their offspring?

In a seminal paper, Shelley Taylor and her colleagues (2000) proposed the tend-and-befriend model as the maternal alternative to the fight-or-flight model of behavioral responses to stress (Taylor, Klein, Lewis, Gruenewald, Gurung \& Updegraff, 2000). Tending, the protection and care of offspring, and befriending, the formation and maintenance of interpersonal relationships with conspecifics, were proposed as strategies that females use in times of stress to defend themselves and their offspring. A stress response geared toward aggression would be non-adaptive for females given their investment in offspring, and the risks they would expose their offspring to if they could not, in times of threat, 
depend on their social network. A central role in the tend-and-befriend model is attributed to oxytocin, which provides the neuroendocrine basis for affiliation with social groups.

Taylor argues than in males, the common stress response would be characterized by fight or flight, activated by androgens (Taylor et al., 2000). The tend-and-befriend model would not be applicable to males due to their low levels of oxytocin and estrogen (Taylor, 2002), while their testosterone levels antagonize affiliation (Wright, Bahrami, Johnson, Malta, Rees, Frith et al., 2012). However, paternal testosterone levels decrease after birth (Gettler, McDade, Feranil \& Kuzawa, 2011) while oxytocin levels increase. The past decade has shown an exponential growth of oxytocin studies with both correlational and experimental designs. The majority of these studies had male participants. Meta-analytically, we found that intranasal oxytocin administration enhances the recognition of facial expressions of emotions, and that it elevates the level of in-group trust (Van IJzendoorn, \& Bakermans-Kranenburg, 2012). In our own studies, we demonstrated increased sensitivity and decreased hostility in fathers' interactive play with their toddlers after intranasal oxytocin administration, both with normally developing children and with children with autism (Naber, Van IJzendoorn, Deschamps, Van Engeland \& Bakermans-Kranenburg, 2010; Naber, Poslawsky, Van IJzendoorn, Van Engeland \& Bakermans-Kranenburg, 2012). Based on these findings, we submit that (naturally or experimentally) heightened levels of oxytocin in males do affect their attitudes and behaviors, including their protective parenting behaviors.

Important questions are what strategy modern parents use to protect their offspring: tend-andbefriend (use of social relationships for protection) or tend-and-defend (aggression against the threatening stimulus), whether these strategies are different for mothers and fathers, and whether protective parenting is influenced by hormone levels. Individual differences in protective parenting have hardly been studied. Although one may be inclined to think that anxious parents may be the most protective parents, this need not be the case. Highly anxious parents may be overwhelmed by cues of threat and freeze rather than protect their offspring, in a similar vein as they can be overwhelmed by their infants' distress (Riem, Bakermans-Kranenburg, Van IJzendoorn, Out, \& Rombouts, 2012a; Rilling, 2013).

\section{Oxytocin and parenting: potential mechanisms}

As we suggested earlier, three perspectives on how oxytocin affects social behavior have been proposed: (i) via anxiety reduction, (ii) by increasing social salience, or (iii) through increasing reward sensitivity. Here we review and discuss how these three mechanisms of OT effects may translate to the parenting context.

First, oxytocin may stimulate sensitive parenting through reduction of anxiety or fear to novelty (Carter, 1998; Heinrichs \& Domes, 2008). The anxiolytic and stress-reducing effects (for a review see Neumann \& Slattery, 2016) have also been indicated in breastfeeding mothers (Heinrichs, Meinlschmidt, Neumann, Wagner, Kirschbaum, Ehlert, et al., 2001). Lactating women either breastfed or held their infants before they were exposed to the Trier Social Stress Test, a psychosocial stressor that robustly evokes increased cortisol levels. Both breastfeeding and holding the infant yielded significant decreases in cortisol levels before the Trier Social Stress Test started. After the stressor, cortisol levels were elevated in all women, but significantly less so in those who had breastfed their infants. Although one may be tempted to ascribe this finding to the oxytocin releasing effect of breastfeeding, it should be noted that oxytocin levels before and after the stressor were not different in the two groups, that is, plasma oxytocin levels did not seem to mediate the suppression of cortisol stress responses. Of course, this leaves open the possibility that central levels of oxytocin were higher in the breastfeeding group and exerted their anxiolytic effect in this group's reactivity to the stressor. This would be convergent with a range of other studies showing correlations of breastfeeding with greater calm and less anxiety compared to formula-feeding mothers (for a review see Mezzacappa, 2004).

Anxiety has been linked to hyperactivity of the amygdala (e.g., LeDoux, 2000; Williams, Kemp, Felmingham, Barton, Olivieri, Peduto, et al., 2006), and nasal administration of oxytocin may 
decrease amygdala hyperactivity, reducing anxiety and aversion, and thereby promoting sensitive parenting. In our lab we found that increased levels of OT in nulliparous females decreased activation of the amygdala during listening to infant cry sounds (Riem, Bakermans-Kranenburg, Pieper, Tops, Boksem, Vermeiren, et al., 2011). Female twins without children of their own were randomly assigned to the OT or placebo condition, and exposed to infant cry sounds of various frequencies. Participants who received oxytocin showed reduced activity in the right amygdala when they listened to infant crying, and increased activity in the insula and the inferior frontal gyrus. Reducing amygdala activation might mean lowering the level of stress and arousal, thus making it possible to engage with a crying child in a more effective way, without being overwhelmed by anxious or aversive feelings. Increased activation of the insula might enhance empathic concern for the distressed baby, in particular when accompanied by elevated activation of the inferior frontal gyrus, which may facilitate understanding of the thoughts and feelings of others. Other studies have shown heightened insula activity during the perception of their own infant in a sad state (Strathearn, Fonagy, Amico \& Montague, 2009), and the inferior frontal gyrus is important for affective prosodic comprehension (Leitman, Wolf, Ragland, Laukka, Loughead, Valdez et al., 2010). This pattern of activation in the OT condition may thus reveal the neural foundation of sensitive parental responding to infant crying.

The role of oxytocin in a novel caregiving context was shown in a study on mothers' peripherally produced oxytocin after close, physical interactions with their own biological children and unknown, unfamiliar children (Bick \& Dozier, 2010). Mother-child dyads did a 25-min computer game that promoted physical contact. Children sat on the mother's lap and the computer game included tickling, whispering to each other, counting while holding each other's hands, and sitting together while listening to short stories. In one session, mothers did the game with their own children and in the other session with unfamiliar children. After the activity, mothers' urine oxytocin levels were higher following interactions with unfamiliar children than following interactions with their own children. This study nicely illustrates how oxytocin reduces anxiety or fear for novelty (and perhaps aversion)- which is more necessary with an unknown child than with one's own child - and thus prepares for sensitive interaction. From an evolutionary perspective it is also implausible that oxytocin would support only parenting of one's own offspring, since throughout history mothers have been dependent on cooperative offspring care to secure enough calories to raise children to the age of independence (Hrdy, 2011).

The second way in which OT may affect parenting is through intensifying the salience of social information (Guastella \& MacLeod, 2012), thereby promoting the processing of social information and attention towards social cues. For example, oxytocin selectively enhances memory encoding of faces in humans (previously presented faces were more correctly assessed as "known"), but not of nonsocial stimuli (Rimmele, Hediger, Heinrichs \& Klaver, 2009, but see Bhandari, Van der Veen, Parsons, Young, Voorthuis, Bakermans-Kranenburg et al., 2014). Increased salience of social information might also explain the differential effects of oxytocin on behavior in different social contexts (De Dreu, Greer, Handgraaf, Shalvi, Van Kleef, Baas, et al., 2010).

In the parenting context it seems plausible that, if oxytocin increases the salience of the context of infant signals, it affects the perception of and responding to an infant's signal. In the case of infant crying, such increased attention towards the context of the cry would be highly adaptive, as it facilitates the interpretation of the infant's crying and helps in selecting an adequate caregiving response. Thus, apart from the acoustics of the infant cry, a range of other factors may guide parental responses to infant crying, such as the infant's facial expression, gestures, and contextual information. Indeed, maternal responses to crying are delayed when the infant has just been fed, indicating that contextual information on the infant's recent caregiving history plays a role in choosing a behavioral response to crying (Bernal, 1972; Leger, Thompson, Merritt \& Benz, 1996). In a similar vein, adults who had been told that an infant needed sleep waited longer to respond to infant crying than those without this information (Wood \& Gustafson, 2001).

In one of our own studies, we tested the effect of intranasally administered oxytocin on the perception of infant crying in systematically varied contexts. We measured neural responses to the same crying sounds in two contexts: once it was indicated as coming from a sick infant, and once as coming from a bored infant. Oxytocin significantly increased insula and inferior frontal gyrus responding to sick infant crying, but decreased activation in these brain regions during exposure to 
crying of an infant that was labeled as bored (Riem et al., 2014). Labeling the same infant crying as 'sick' or as 'bored' thus drastically changed neural activity in response to intranasal oxytocin administration. Through increased salience of the contextual information, high OT levels may promote empathic reactions to sick infants' crying, and lower the perceived urgency of crying of an infant who is merely bored, thus allowing for flexible adaptation to the broad range of infant crying episodes that parents have to deal with.

The third documented effect of OT is that it increases reward sensitivity (Bethlehem, BaronCohen, Van Honk, Auyeun \& Bos, 2014), which is not unimportant in the challenging life of a new parent. Infants start their extra-uterine life crying, and it takes a while before their behavioral repertoire includes smiling and laughter. But once infants smile, they have won their parents, for infant laughter is a rewarding experience. It provokes feelings of love and happiness and promotes infant survival by eliciting parental proximity and care (Bowlby, 1969/1982; Groh and Roisman, 2009; Mendes, Seidl-de-Moura \& Siquereira, 2009). Laughter is probably the outcome of a long evolutionary history (Van Hooff, 1972), and infant smiling is one of the basic attachment behaviors that create closer proximity to a protective caregiver (Bowlby, 1969/1982; Sroufe and Waters, 1976). The infant's laughter may activate neural reward centers in the parental brain (Kringelbach, 2005; Kringelbach et al, 2008; Strathearn et al, 2009) and doing so reinforces parental playful interactions with the child.

The physiological effects of infant smiles on their parents have been demonstrated when firsttime mothers viewed films of their own 6- to 7-month-old infants' affective behavior (Mizugaki, Maehara, Okanoya \& Myowa-Yamakoshi et al., 2015). They were shown a video of a distress cry followed by a video showing either a happy smiling face or a calm neutral face. In the smile condition, but not in the neutral condition, the mothers showed deceleration of skin conductance, indicating decreased sympathetic activity. Not only may increased OT levels as a result of the smiling infant video be partly responsible for the decreased sympathetic activity, but variance in OT levels may also account for differences in the perception of infant smile and laugther. Oxytocin may intensify the reward associations of the infant by increasing the release of opiates (Depue \& Morone-Strupinsky, 2005), and may thus enhance the incentive salience of infant laughter. Germane to this issue is the association between lower plasma OT levels and depressive symptomatology (Gordon, ZagoorySharon, Schneiderman, Leckman, Weller \& Feldman, 2008; for a review on oxytocin and postnatal depression see Mah, 2016). Postnatally depressed mothers have been found to respond less to their infants' vocalizations and laughter at 3 months (Righetti-Veltema, Conne-Perréard, Bousquet \& Manzano, 2002), and it may well be that lower OT levels in postnatally depressed mothers account for their reduced reactivity to infant smiling and laughter.

In a randomized controlled trial we investigated the influence of intranasally administered oxytocin on functional brain connectivity in response to infant laughter. Elevated oxytocin levels reduced activation in the amygdala during infant laughter and enhanced functional connectivity between the amygdala and the orbitofrontal cortex, the anterior cingulate, the hippocampus, the precuneus, the supramarginal gyri, and the middle temporal gyrus (Riem, Van IJzendoorn, Tops, Boksem, Rombouts \& Bakermans-Kranenburg, 2012b). Frontostriatal brain regions are critically implicated in reward, in particular the orbitofrontal cortex (Kringelbach et al., 2008). Increased functional connectivity between the amygdala and regions involved in emotion regulation reduce negative emotional arousal while they enhance the incentive salience of infant laughter. Oxytocin may thus support playful interaction and parent-infant bonding by increasing the reward value of the infant's pleasure during parent-child interaction.

\subsection{Oxytocin in sensitive and protective parenting}

\subsubsection{Sensitivity}

Returning to the three-stage process of sensitive parenting (Ainsworth et al., 1974), the sensitive parent should (1) notice the child's signals, (2) interpret these signals correctly, and (3) give a 
behavioral response that is prompt and appropriate. The involvement of oxytocin in each of these three steps seems to underline its significance for facilitating sensitive parenting.

Starting with the behavioral response, there is ample correlational evidence of a link between higher salivary or plasma levels of oxytocin and more sensitive parenting (but see Elmadih, Wan, Numan, Elliot, Downey \& Abel, 2014). Higher maternal oxytocin levels across pregnancy were found to predict higher quality of postpartum maternal behavior (Feldman, et al., 2007). At 2 weeks postpartum, higher maternal plasma levels of OT were associated with more positive maternal behavior, a combination of gaze, positive affect, affectionate touch, and motherese vocalizations (Feldman, et al., 2007). At 6 months triadic synchrony in mother-father-infant interactions, defined as moments of coordination between physical proximity and affectionate touch between the parents and parent and infant, was predicted by both maternal and paternal OT (Gordon, Zagoory-Sharon, Leckman \& Feldman, 2010).

Mothers and fathers may be equivalent as sensitive parents, but not similar in their parenting behavior and its hormonal substrate. Differences in the association between mothers' and fathers' parenting behavior and oxytocin reactivity have been found. When mothers and fathers engaged in a playful interaction session with their 4- to 6-month-old infants, their baseline levels of plasma and salivary oxytocin were moderately associated and similar in mothers and fathers, but salivary oxytocin levels were associated with specific modes of interaction in mothers and fathers. Whereas maternal oxytocin levels were positively associated with affectionate touch, paternal oxytocin was uniquely associated with stimulatory contact, but not affectionate touch. Furthermore, oxytocin increases following interactions with their infants were observed in highly affectionate mothers and highly stimulating fathers (Feldman, Gordon, Schneiderman, Weisman \& Zagoory-Sharon, 2010). This gender difference fits in with the idea that maternal sensitivity is typically expressed as emotional warmth and support whereas paternal sensitivity frequently manifests as the provision of stimulating interactions (K. Grossmann, K.A. Grossmann, Kindler \& Zimmermann, 2008).

In an experimental counterpart to the Feldman et al. (2010) correlational study, Naber et al. (2010) administered oxytocin or placebo to fathers in a double-blind, placebo-controlled, withinsubject experiment observing fathers and their toddlers in two play sessions, with an intervening period of 1 week. In the oxytocin condition fathers were less hostile and more stimulating of their child's exploration than in the placebo condition. This result was replicated in a sample of fathers of children with autism spectrum disorder (Naber et al., 2012), showing the robustness of the effect. So, while a correlational study found increased OT in fathers after stimulatory play (Feldman et al., 2010), experimentally increased OT levels in turn led to more stimulatory play (Naber et al., 2010; 2012); a nice example of hypothesis generating and hypothesis testing in two related studies from different labs. The experimental study was also the first to show that OT administration affected observed parenting behavior.

On the 'dark' side of the continuum of parental sensitivity are hostility and harsh parenting responses, and infant crying is one of the major triggers of such responses (Reijneveld, Van der Wal, Brugman, Sing \& Verloove-Vanhorick, 2004). To examine the effect of oxytocin on the inclination to respond harshly to infant crying, we used a hand-grip dynamometer (Bakermans-Kranenburg, Van IJzendoorn, Riem, Tops \& Alink, 2012). Hand-grip dynamometer data have been more often used as a measure of the use of excessive force in (pseudo-)parenting contexts. For example, Crouch, Skowronski, Milner \& Harris (2008) had parents at high and low risk for child physical abuse use a hand dynamometer when they watched video clips of an infant in quiet, smiling, and crying states. After negative priming, at-risk parents tended to use more excessive force when asked to produce a half-strength grip. In a study on punitive force, women who perceived themselves as low in power used more excessive force than other women when children were ambiguously responsive in a simulated computer interaction (Bugental, Lewis, Lin, Lyon \& Kopeikin, 1999). In our randomized controlled study, participants in the oxytocin condition less often used excessive force when exposed to infant cry sounds, but this was only true of parents who had experienced no or little harsh parenting themselves. For participants who were disciplined harshly in their own childhood oxytocin was not effective in decreasing the use of too much physical force in response to infant crying. Early caregiving experiences may thus constitute an important moderator of the effects of oxytocin (Bakermans-Kranenburg \& Van IJzendoorn, 2013). 
Recently however we showed that OT administration can decrease the use of excessive handgrip force and amygdala reactivity in response to crying in individuals with insecure attachment representations (Riem et al., 2016). Insecure parents tend to make negative internal attributions to the nature of infant crying (e.g., the child is spoiled or has a difficult temperament) and are less accurate at identifying infant emotions (Leerkes \& Siepak, 2006). This negative perception of the cry makes it more difficult to respond in a sensitive way (Dykas \& Cassidy, 2011). Indeed, women with insecure attachment representations showed heightened amygdala activation when exposed to infant crying compared to women with secure attachment representations, and experienced more irritation during infant crying than women with a secure representation (Riem, et al., 2012a). This hyperreactivity to infant crying was diminished after intranasal oxytocin, and the findings suggest that dampening of amygdala activity may play a mediating role in the lowered feelings of irritation, paving the way for a more sensitive reaction to the child's distress.

That brings us to the perception and processing of infant signals. Imaging studies have shed light on the 'black box' between infant signal and parental response - although the gap between neuroimaging and behavioral data is not easily bridged (ref gap). In a review of the literature on the parental brain, Swain et al. (2014) proposes that cortico-limbic brain networks interact to support parental responses to infants and regulate parental sensitivity. These networks would include circuitries for arousal (salience and reward), reflexive caring, emotion regulation, and integrative cognitive processing. Neuroimaging studies suggest that these networks are also associated with OT pathways; a multimodal voxel-based meta-analysis indicated that brain regions of the 'maternal brain' circuitry (brain regions that show increased neural responses to cues from own infants vs. other infants) overlapped with the regions showing an effect of OT administration, in particular the bilateral insula, amygdala, thalamus, left basal ganglia, and the bilateral frontotemporal cortex (Rocchetti, Radua, Paloyelis, Xenaki, Frascarelli, Caverzasi et al., 2014).

This may explain why mothers who had a vaginal delivery showed more brain activity when exposed to own vs. other baby-cry in emotion regulation and limbic regions, including the caudate, thalamus, hypothalamus, and amygdala than mothers who had a cesarean delivery and thus lower OT levels (Swain, 2008). In a similar vein, compared to formula feeding mothers, mothers who breastfed (accompanied by higher OT levels) showed greater activations to own baby cries vs. other baby cries in anterior and posterior cingulate, thalamus, midbrain, hypothalamus, septal regions, dorsal and ventral striatum, medial prefrontal cortex, right orbitofrontal/insula/temporal polar cortex region, and right lateral temporal cortex and fusiform gyrus (Kim, Feldman, Mayes, Eicher, Thomson, Leckman et al., 2011). As one of the few studies bridging the brain-behavior gap, this study also showed that activity in the right superior frontal gyrus and amygdala was associated with higher maternal sensitivity at 3-4 months of the infant's age. Directly relating plasma oxytocin levels to neural activity while observing own-infant compared with standard-infant videos, Atzil and colleagues (2012) found positive correlations with activation in the left insula, left IPL, left and right temporal cortices, left ventral ACC, and left NAcc. Fathers' OT levels negatively correlated with the left inferior and superior frontal gyrus, left primary motor cortex, medial PFC, and left ACC.

\subsubsection{Protective parenting}

In rodents the role of oxytocin in parental protection has been amply tested and demonstrated (Bosch, Meddle, Beiderbeck, Douglas \& Neumann, 2005). When an intruder is placed in the cage of a Wistar rat dam with her pups, the dam's offensive attacks are positively related to oxytocin release in the paraventricular nucleus (PVN) and the central nucleus of the amygdala (CeA). Moreover, blockade of endogenous oxytocin action reduces maternal aggression, whereas infusion of synthetic oxytocin tends to increase aggression toward the intruder. In untreated rats, the intensity of maternal aggression increases to a maximum during early lactation, around days 4 to 7 , and disappears at weaning. This aggression curve is similar in shape when compared to oxytocin levels: oxytocin receptor binding in the lateral septum correlates with the peak of maternal aggression (Caughey, Klampfl, Bishop, Pfoertsch, Neumann, Bosch et al., 2011). The strong increase in oxytocin in lactating rats thus also promotes defending the offspring against potential threats. 
Moreover, oxytocin levels have been linked to the better detection and avoidance of actual or potentially disease-infected mice and rats (Kavaliers, Choleris, Ågmo \& Pfaff, 2004). The olfactory system plays a major role in this process. Female mice treated with an OT antagonist were specifically impaired in their ability to discriminate the odors of healthy versus infected males. This suggests that OT is part of the central mechanisms mediating the avoidance of infected conspecifics. Other evidence for this suggestion comes from studies on voles, a favorite animal model for OT studies. Female prairie voles, with relatively high OT activity, avoid the odor of potentially infected males, whereas female meadow voles, with relatively lower OT activity, cannot discriminate the odors of infected and healthy males (for a review, see Kavaliers et al, 2004). Moreover, infusion of an OT receptor antagonist into the medial amygdala reduced the ability to discriminate between individual odors in the prairie voles (H. Arakawa, K. Arakawa \& Deak, 2010).

Human protective parenting starts not after birth, but can be observed already during pregnancy. Mothers are well-equipped protectors during pregnancy, although most of the pregnant females do not recognize their morning sickness or increased aversion from specific foods as protective pathogen avoidance. Although morning sickness during pregnancy could be a by-product of the conflict between the mother and the embryo (Forbes, 2002, Sadedin, 2014), the aversion to food appears to be functional: pregnant mothers tend to avoid foods that are more likely to carry pathogens, in particular meat (Flaxmann \& Sherman, 2000), that can be particularly harmful in the first trimester of the pregnancy, when the fetus is without key immune defenses. Morning sickness and vomiting thus seem to reflect adaptive shifts in food preferences - which is further supported by a cross-cultural study showing higher rates of morning sickness in countries with higher consumption of foods that could harm the fetus (Pepper \& Roberts, 2006). Note that this sickness, and the concomitant lower maternal food intake, peaks during the early pregnancy weeks, with low caloric demands, so it does not harm the growth of the fetus (Fessler, 2002); actually, children of mothers with pregnancy sickness have more positive health outcomes than children of mothers without these symptoms (Furneaux, A.J. Langley-Evans \& S.C. Langley-Evans et al., 2001). Which hormones are responsible for morning sickness is as yet unclear. Progesterone has been suggested as a candidate, because it can induce sickness in non-pregnant women, and because mothers of twins have increased progesterone levels as well as more pregnancy sickness (Fessler, 2002). But since morning sickness tends to decrease after the first three months of pregnancy, while progesterone levels increase throughout pregnancy, a critical role for progesterone in pregnancy sickness is not plausible.

Interestingly, the instinctive avoidance of harmful pathogens by pregnant women is not limited to food. Pregnant and non-pregnant women were shown four pairs of faces and asked to choose which face they preferred. The pairs of male faces varied in apparent health (e.g., pallor) but were matched in other respects. Healthy faces were favored by pregnant women to a larger extent than by non-pregnant women (Jones, Perret, Little, Boothroyd, Cornwell, Feinberg et al., 2005).

Apparently, pregnant women are more sensitive to facial cues of ill health as something to avoid, to protect their developing fetus. Oxytocin may play a role in this context, as it does in mice and voles. Human mothers show a pattern of gradual rise of oxytocin levels with advancing gestation and peak values after birth (De Geest, Thiery, Piron-Possuyt, \& Van den Driessche, 1985). Therefore, the protective recognition of illness in others, boosted by oxytocin, may increase during pregnancy and be particularly relevant after birth, during the first weeks of the infant's vulnerable life. Further evidence for the role of oxytocin in the awareness and avoidance of potentially harmful filth comes from a study with OT administration (Theodoridou, Penton-Voak \& Rowe, 2013) where participants were asked to move a lever toward or away from pictures of faces depicting emotional expressions appearing before them on a computer screen. The oxytocin group was faster in their reactions to faces depicting disgust relative to the placebo group, suggesting increased salience of disgust after sniffing OT.

It is not difficult to see how the three mechanisms of oxytocin effects on social interaction (anxiety reduction, increased salience of social cues, increased reward sensitivity) can play their roles in enhancing protective parenting. The consequences of oxytocin's reward-increasing effects on protective parenting are evident. Infants are highly rewarding attachment objects that elicit pleasure, but such sources of reward also heighten distress if parents perceive them as in danger - the degree of alarm is increased by the very same means that increases the reward function of the infant. 
The reduction of fear realized by increased OT levels facilitates the use of aggression. Although Taylor and colleagues (2000) argued that for females a stress response geared toward aggressing would be non-adaptive given their investment in offspring, females do attack as well. Oxytocin levels have been directly correlated with maternal defense (Campbell, 2008; Caughey et al., 2011). Lactating human mothers behave more aggressively than nonlactating mothers toward fellow participants in a competitive game. Reduced physiological arousal (as indicated by systolic blood pressure) mediated the effect of breast feeding on aggression (Hahn-Holbrook, Holt-Lunstad, Holbrook, Coyne, \& Lawson, 2011). This once more points to a role of oxytocin. The idea that oxytocin facilitates bonding to offspring, mates, and kin, such that oxytocin may intensify aggressive behavior on behalf of these affiliates when they are threatened is not new (Campbell, 2008). In line with this model, but not in a parenting context, in males oxytocin administration increased aggression in defense of an experimentally defined in-group (De Dreu et al., 2010; see Chapter Y).

The role of OT in increasing salience of social cues in the context of protection has been indicated already in the faster reactions to faces depicting disgust after OT administration (Theodoridou et al., 2013). In a somewhat similar vein, Striepens and colleagues (2012) showed that administration of oxytocin increased the startle reflex for sound bursts shown during negative pictures, and promoted a memory bias toward negative information at the cost of neutral information, thus an increased focus on potentially threatening aspects of the environment. As discussed before, we found a similar effect of increased salience of infant crying labeled as coming from a sick child compared to crying coming from a bored child. Alarming social cues -but not neutral cues-- seem to trigger more neural activity in the oxytocin condition than in the placebo condition (Riem, Voorthuis, BakermansKranenburg \& Van IJzendoorn, 2014).

\subsubsection{A measure of protective parenting}

The observation of protective parenting in an ecologically valid way provides a puzzle for researchers. The use of real threats is ethically unacceptable. For the observation of protective parenting and the potential role of oxytocin, we developed the Enthusiastic Stranger Paradigm (Mah, Bakermans-Kranenburg, Van IJzendoorn \& Smith, 2014). and used it in a double-blind, randomizedcontrolled, within-subject design with oxytocin and placebo administration in a group of mothers with a diagnosis of postnatal depression (PND). While sitting in a waiting room with the infant on the floor at some distance from its mother, an unknown adult (the 'Stranger') entered the room. The stranger apologized for the interruption and pretended to be present for the purposes of a work related reason (looking for another staff member during the first visit and checking smoke detectors during the second). Very soon after entering however, the stranger noticed the infant, made a comment such as "What a lovely baby" and then moved toward the infant. Strangers sought neither verbal nor nonverbal permission from the mother, but they were alert to any resistance from the part of the parent. In a socially intrusive manner the stranger attempted to engage the baby, aiming to elicit a number of smiles. In the final stage of the approach, the stranger touched the baby on the shoulder or cheek unless the mother stopped her. The stranger then apologized for the interruption and left the room.

Maternal protection was coding on a rating scale ranging from 1 (no or brief glances toward the stranger) to 5 (active and direct attempts to stop the stranger, using motor and/or verbal behavior). In the OT condition mothers were significantly more protective of their baby in the presence of a stranger, and the effect of OT was independent of level of mothers' depression. We are currently replicating our findings in a sample of fathers and in non-depressed mothers. This Enthusiastic Stranger Paradigm may be an ethically acceptable procedure, taking no more than three minutes, to assess protective parenting in a very life-like manner: All parents know how neighbors and strangers alike curiously peek into the pram to have a close-up of a baby and try to touch its cheeks. How this protective response and its modulation by oxytocin is dependent on culture, ethnicity, socioeconomic status or customs remains to be seen. 


\subsection{Other hormones in sensitive and protective parenting}

Notably, it is implausible that oxytocin would be the only hormonal factor in sensitive and protective parenting. A second hormone that is probably involved in parenting and protection is testosterone. In many species where males are involved in offspring care, including humans, testosterone levels decrease during fatherhood (Storey, Walsh, Quinton \& Wynne-Edwards, 2000; Wynne-Edwards \& Reburn, 2000). Fathers with lower basal testosterone levels show more optimal parenting behavior (Weissman, Zagoory-Sharon \& Feldman, 2014) and feel more sympathy when listening to infant cries (Fleming, Corter, Stallings \& Steiner, 2002). Although in general testosterone is thus considered antagonistic to sensitive parenting, and related to investment in mating rather than in parenting efforts, heightened testosterone in parents may point to an action preparatory response. There is an optimal range of activation that supports appropriate parenting (Rilling, 2013; Reijman, Alink, Block, Werner, Maras, Rijnberk et al., 2014; Reijman, Alink, Compier-de Block, Werner, Maras, Rijnberk et al., 2015). Whereas over-activation could lead to over-arousal and harsh parenting, under-activation of the amygdala and insula may lead to insufficient response, resulting in neglect. Testosterone administration increases amygdala reactivity (Bos, Hermans, Montoya, Ramsey \& Van Honk, 2010), and the amygdala may play a central role in protective parenting responses. The amygdala functions as an "alarm" to relay signals of threat. Exposure to cry stimuli can increase fathers' testosterone levels (Fleming et al., 2002), which prepares them for action. Interestingly, one study showed that males' testosterone levels increased when they listened to infant cries and no protective or caregiving response was possible, but their testosterone levels decreased when they could provide active care (Van Anders, Tolman \& Volling, 2012). Apart from its direct signaling function, testosterone may exert its effects also indirectly: In the central nervous system, testosterone is metabolized to estradiol, which in turn is critical for the synthesis of oxytocin (Choleris, Devidze, Kavaliers \& Pfaff, 2008). This indirect way could also explain the heightened activity in the thalamocingulate region, insula, and the cerebellum in response to crying after testosterone administration in young females (Bos et al., 2010).

An intriguing issue is the interplay between oxytocin and cortisol in protective parenting. A certain level of parental anxiety may be needed to alert parents to potential threats, whereas oxytocin tends to suppress activity of the HPA axis. First-time mothers with higher cortisol concentrations were more attracted to their own infant's body odor. Mothers with higher cortisol levels were also better able to recognize their own infants' odors (Fleming, Steiner \& Corter, 1997), and engaged in more affectionate approach responses with their infants (Fleming, Steiner \& Anderson, 1987). Mothers with high baseline salivary cortisol levels also showed more sympathy in response to cries of newborn infants (Stallings, Fleming, Corter, Worthman \& Steiner, 2001).

Moreover, cortisol and testosterone may interact. Traits associated with high testosterone have been suggested to manifest more in individuals with low basal cortisol (Mehta \& Josephs, 2010), because cortisol can inhibit the secretion of testosterone at all levels of the Hypothalamic-PituitaryGonadal axis (HPG axis), and testosterone can inhibit cortisol secretion by acting upon the hypothalamus (Viau, 2002). Zilioli, Ponzi, Henry and Maestripieri (2014) showed that in males lower self-reported empathy was related to higher testosterone in individuals with low basal cortisol, whereas in individuals with high basal cortisol testosterone and empathy were positively associated. However, in females high testosterone was related to reactive aggression only in individuals with high basal cortisol (Denson, Mehta \& Tan, 2013), which may point to more testosterone-related protective aggression in females with elevated cortisol levels - who as suggested above may be the ones with the strongest bonding to their infants.

Prolactin stimulates parental care, and may promote protective parenting as well. Prolactin levels increase during pregnancy in mothers, but also in fathers (Storey et al., 2000). Fathers occasionally experience pregnancy symptoms, including weight gain, nausea, fatigue, and emotional instability, particularly in cultures with high levels of intimacy between the partners and involvement of fathers in caregiving of the baby (Elwood \& Mason, 1994). In a Canadian sample, fathers reporting two or more pregnancy symptoms had higher prolactin levels than fathers with fewer symptoms (Storey et al., 2000). Interestingly, fathers with higher prolactin levels also felt more concerned in response to baby cries. 
Another candidate is estradiol, which is the primary female sex hormone. After childbirth, estradiol and oxytocin act in concert to promote mother-infant bonding (Kendrick, 2000; Insel \& Young, 2001). In a small sample of males, however, first expecting and then caring for their first child was not related to changes in basal levels of estradiol (Berg \& Wynne-Edwards, 2002). Fathers' play with their toddlers also did not affect their estradiol levels (Gettler, McDade, Agustin \& Kuzawa, 2013). As noted above, estradiol, as a metabolite of testosterone, plays a role in the balance between testosterone and oxytocin.

Last but not least, vasopressin enhances the endocrine stress response, and counterbalances the stress-reducing effects of oxytocin. The synthesis of vasopressin is facilitated by androgens, which results in higher levels of vasopressin in males than in females (Carter, 1998). The structure of vasopressin is very similar to that of oxytocin, and the similarity of the two peptides can cause crossreactions. Thus, high doses of oxytocin administration may lead to binding of oxytocin to vasopressin receptors, shifting the balance between oxytocin and vasopressin in the brain (Gimpl \& Fahrenholz, 2001). After mating vasopressin levels in males are elevated, leading to increased territoriality and partner protection (Carter, 1998). In rats, vasopressin is involved in the detection and avoidance of infected conspecifics (Arawaka et al., 2010) and can facilitate maternal behavior, and in one study, human fathers with low vasopressin levels showed more cognitive processing when observing their own infant (Atzil, Hendler, Zagoory-Sharon, Winetraub \& Feldman, 2012). Effects in humans may be sexually dismorphic: intranasal AVP increased the perception of friendliness in females, but decreased it in males (Thompson, George, Walton, Orr \& Benson, 2006).

\subsection{A model of sensitive and protective parenting}

Oxytocin does not work in isolation in affecting parental sensitivity, and although research on human parental protection is still in its infancy, there are good reasons to expect that oxytocin works in concert with other neuropeptides and hormones in its influence on protective parenting as well.

Whereas high levels of oxytocin are generally associated with more sensitive parenting and tend-andbefriend socially established protection of offspring, we submit that testosterone and vasopressin may

be involved in the more active, if necessary
aggressive, modalities of protective
parenting, Testosterone has been related to
lower parental sensitivity, but may also
indirectly promote sensitive parenting: In
the central nervous system, testosterone is
metabolized to estradiol, which in turn is
critical for the synthesis of oxytocin
(Choleris et al., 2008). This is only one
illustration of the many interdependencies of
the components of the model. A second
example is cortisol, which interacts with
both oxytocin and testosterone in its
influence on sensitive and protective
parenting. Progesteron and prolactine have
not been included in the model, because
their roles in sensitive and protective
parenting still have to be examined more
carefully.

\subsection{Outstanding questions and future research}

Less than two decades of research on oxytocin have firmly established its role in human parenting, both as a neurotransmitter and as a hormone. Given the modest number of years of research 
on oxytocin and parenting, remarkable progress has been made. That is not to say that there are no outstanding questions left - some of them are even quite basic, and constitute the research program for the next years, for oxytocin research in general and for its role in sensitive and protective parenting in particular.

A crucial issue is that the effects and mechanisms of oxytocin can only be reliably revealed by randomized controlled experimental studies. After the first generation of studies with intravenous administration in the seventies of the last century, an upsurge of experimental research with nasal administration of oxytocin starting around the turn of the century could be observed. These seem to be more successful, although it is still not crystal clear whether and how oxytocin sniffs reach the oxytocin-receptor rich areas of the brain (Churchland \& Winkielman, 2012; Kagerbauer, Martin, Schuster, Blobner, Kochs \& Landgraf, 2013, see Quintana, Guastella, Westlye \& Andreassen, 2016; Van IJzendoorn \& Bakermans-Kranenburg, 2016), and more studies are needed to examine the various direct and indirect pathways hypothesized to lead oxytocin to relevant brain regions. However, it may not be possible or safe to conduct such studies in pregnant females, given the labor-inducing effect of oxytocin, and correlational studies may be the only means we have to gain more knowledge about the role of oxytocin in prenatal sensitive and protective parenting. After birth the huge fluctuations in endogenous maternal oxytocin levels need to be taken into account, complicating experimental studies. Fathers are biologically easier targets for such studies, but although males were the preferred gender to be included in the first wave of oxytocin administration studies (with around $80 \%$ of the participants being males), the majority of these studies pertained to trust or spending virtual money, and not to parenting. So far, only two RCTs focused on fathering (Naber et al., 2010, 2012) notwithstanding the fact that roughly $50 \%$ of the parents are fathers and that most males are or will become fathers.

This means that in oxytocin studies of non-parental behavior males appear most frequently, but in studies on parenting females play the leading part. In both types of studies, effects may not be generalizable to the other gender. Given the increased participation of fathers in parenting in most western countries over the past decades, there is an urgent need for greater insight into the hormonal and behavioral dynamics of the paternal role. Paquette (2004) distinguished two dimensions of fathering that are specific for the father-child relationship: stimulation, wherein fathers encourage the child's interaction with the outside world, and discipline, to provide children with limits that protect their safety during that exploration (Paquette, 2004). This means that fathers need to effectively assess external contextual factors to determine whether situations are sufficiently safe to encourage the child's engagement with the broader environment. Their neurobiology may equip them with the necessary means for this continuous assessment and protective intervention when needed, whereas mothers may be more focused on nurturing care. Oxytocin may play a differential role in fathers' and mothers' protective parenting. However, it may well be that fathers need to have children of their own before their protective parenting system is activated. One recent study found that priming with caregiving (remembering the first few days after giving birth to their first child) was related to increased derogation of threatening out-groups (Gilead \& Liberman, 2014). Of note, effects were stronger for males with children than for males without children of their own, whereas no such difference was found in females, suggesting that for males the transition to fatherhood strengthens their motivation to protect.

The effects of exogenous oxytocin may be dependent not only on contextual factors (Olff, Frijling, Kubzansky, Bradley, Ellenbogen, Cardoso et al., 2013; De Dreu et al., 2010), but also on personal characteristics, most notably gender, endogenous levels of oxytocin, and early childhood experiences. Several studies have pointed to the differential consequences of experimentally manipulated oxytocin levels in males vs. females (Domes, Heinrichs, Gläscher, Büchel, Braus \& Herpertz, 2007; Domes, Lischke, Berger, Grossmann, Hauenstein, Heinrichs et al., 2010), and although hardly studied in relation to parenting behavior, the combined correlational and experimental evidence from Feldman et al. (2010) and Naber and colleagues (2010,2012) suggests that oxytocin may stimulate parent-specific behaviors. That the gender-specificities of parenting behavior and brain reactivity to infant signals are not set in stone, however, is evident from a study with primarycaregiving homosexual fathers (Abraham, Hendler, Shapira-Lichter, Kanat-Maymon, Zagoory-Sharon \& Feldman, 2014). In response to infant stimuli, primary-caregiving mothers showed greater activation in the emotional processing network and their male partners in the socio-cognitive circuits, 
which were differentially linked with oxytocin and behavior. Primary-caregiving fathers showed high amygdala activation, similar to mothers, and among all fathers, time spent in childcare correlated with connectivity between the amygdala and the superior temporal sulcus, demonstrating the effect of caregiving experiences on brain reactivity to infant signals.

Endogenous levels of oxytocin may also play a role in introducing variability of the effects of oxytocin, with individuals with lower basal levels showing stronger reactions to a sniff of oxytocin. Not too many studies report on basal levels of oxytocin before a sniff is administered. It may be the case that the current doses of oxytocin in experimental studies overrule any variance in basal level, but this points to another question: can we infer the effects of endogenous oxytocin levels if in our experimental studies the dose of exogenous oxytocin is so high that the increase in peripheral levels is hundredfold in salivary levels?

Furthermore, several studies showed smaller or absent effects of intranasal oxytocin in individuals with unsupportive caregiving experiences (for a review see Bakermans-Kranenburg \& Van IJzendoorn, 2013). This may be related to these individuals' cognitive representation of the social environment (perception of others as either a potential threat rather than a friendly conspecific), or with epigenetic changes at the oxytocin receptor level (Champagne, 2008; Kumsta, Hummel, Chen \& Heinrichs, 2013). Altered receptor density, affinity, or function at the oxytocin receptor level may be related to experience-dependent methylation of genetic areas regulating the oxytocin system.

Differences in genetic expression may, in turn, lead to decreased sensitivity to intranasal oxytocin. Vasopressin may play a role in this moderating effect. Vasopressin is part of the stress-related HPA axis system, suggesting that early-life stress, which increases vasopressin levels, could alter the subsequent sensitivity of the oxytonergic system. Male rats injected with vasopressin during the first week of life had reduced gene expression for the oxytocin receptor in the paraventricular nucleus during adulthood (Ostrowski, 1998), and as adults showed more aggression toward intruders (Stribley \& Carter, 1999). It is this moderation by unfavorable early childhood experiences that may limit the effectiveness of OT as a stand-alone pharmacotherapeutic drug for those who are most in need of parenting support.

Lastly, the brain-behavior gap is not easily bridged, and it needs more attention and research efforts. Changes in neural activity in response to infant stimuli as a result of experimentally increased oxytocin levels are not accompanied by behavioral changes as often as one would expect. That is true in our own studies (Riem et al., 2016; Voorthuis, Riem, Van IJzendoorn, Bakermans-Kranenburg, 2014), and may be true in other labs as well. Unfortunately, not all of these results may have been published (Lane, Luminet, Nave, \& Mikolajczak, 2016) - which would lead to an underestimation of the problem. Part of the scarcity of documented brain-behavior links may be attributed to underpowered studies. Most of these studies - and this is true for studies on oxytocin more general include a small to modest number of subjects and thus are seriously underpowered, which implies a high risk for publication bias and nonreplicability. Nevertheless, the picture is not too gloomy. The superior power of within-subject designs often used in this area should be acknowledged, and oxytocin studies using this design might yield results that can be replicated more easily than studies with other designs (see Van IJzendoorn \& Bakermans-Kranenburg, 2016). Examining the hormonal, neural, and behavioral mechanisms of parenting in tandem is crucial for the development of theory on the interplay between neuroscience and parenting, and for the identification of "biomarkers" for insensitive and unprotective parenting behaviors useful in preventive parenting interventions. 


\section{References}

Abraham E, Hendler T, Shapira-Lichter I et al (2014) Father's brain is sensitive to childcare experiences. Proc Natl Acad Sci USA 111:9792-9797

Abramowitz JS, Schwartz SA, Moore KM (2003) Obsessional thoughts in postpartum females and their partners: content, severity, and relationship with depression. J Clin Psychol Med S 10(3):157-164

Agran PF, Anderson C, Winn D et al (2003) Rates of pediatric injuries by 3-month intervals for children 0 to 3 years of age. Pediatrics 111(6):e683-e692

Ainsworth MDS (1967) Infancy in Uganda. Johns Hopkins, Baltimore

Ainsworth MDS, Bell S, Stayton D (1974) Infant-mother attachment and social development. In: Richards MP (ed) The introduction of the child into a social world. University Press, Cambridge, p 99-135

Arakawa H, Arakawa K, Deak T (2010) Oxytocin and vasopressin in the medial amygdala differentially modulate approach and avoidance behavior toward illness-related social odor. Neurosci 171:1141-1151

Atzil S, Hendler T, Zagoory-Sharon O et al (2012) Synchrony and Specificity in the Maternal and the Paternal Brain: Relations to Oxytocin and Vasopressin. J Am Acad Child Adolesc Psychiat 51(8):798-811

Bakermans-Kranenburg M J, Van IJzendoorn MH, Juffer F (2003) Less is more: meta-analyses of sensitivity and attachment interventions in early childhood. Psychol bull 129(2): 195-215

Bakermans-Kranenburg MJ, Van IJzendoorn MH (2013) Sniffing around oxytocin: review and meta-analyses of trials in healthy and clinical groups with implications for pharmacotherapy. Transl Psychiat 3(5):e258

Bakermans-Kranenburg MJ, Van IJzendoorn MH (2017). Protective Parenting: Neurobiological and behavioral dimensions. Current Opinion in Psychology 15: 45-49

Bakermans-Kranenburg MJ, Van IJzendoorn MH, Riem MME et al (2012) Oxytocin decreases handgrip force in reaction to infant crying in females without harsh parenting experiences. SCAN 7:951-957

Berg SJ, Wynne-Edwards KE (2002) Salivary hormone concentrations in mothers and fathers becoming parents are not correlated. Horm Behav 42:424-436

Bernal J (1972) Crying during the first 10 days of life, and maternal responses. Dev Medic Child Neurol 14(3):362-372

Bethlehem RAI, Baron-Cohen S, Van Honk J et al (2014) The oxytocin paradox. Front Behav Neurosci 8(48):15

Bhandari R, Van der Veen R, Parsons CE et al (2014) Effects of intranasal oxytocin administration on memory for infant cues: Moderation by childhood emotional treatment. Soc Neurosci 9(5):536-547

Bick J, Dozier M (2010) Mothers' and children's concentrations of oxytocin following close, physical interactions with biological and non-biological children. Dev Psychobiol 52(1):100-107

Bos PA, Hermans EJ, Montoya ER et al (2010) Testosterone administration modulates neural responses to crying infants in young females. Psychoneuroendocrinology 35:114 -121

Bosch OJ, Meddle SL, Beiderbeck DI et al (2005) Brain oxytocin correlates with maternal aggression: link to anxiety. J Neurosci 25(29):6807-6815

Bowlby J (1969/1982) Attachment. Volume 1: Attachment and Loss. Penguin Books, Harmondsworth 
Bugental DB, Lewis JC, Lin E et al (1999) In charge but not in control: The management of teaching relationships by adults with low perceived power. Dev Psychol 35(6):1367

Campbell A (2008) Attachment, aggression and affiliation: the role of oxytocin in female social behavior. Biol Psychol 77:1-10

Carter CS (1998) Neuroendocrine perspectives on social attachment and love. Psychoneuroendocrinology 23:779-818

Caughey SD, Klampfl SM, Bishop VR et al (2011) Changes in the intensity of maternal aggression and central oxytocin and vasopressin V1a receptors across the peripartum period in the rat. J Neuroendocrinol 23:1113-1124

Champagne FA (2008) Epigenetic mechanisms and the transgenerational effects of maternal care. Front Neuroendocrinol 29(3):386-397

Choleris E, Devidze N, Kavaliers M et al (2008) Steroidal/neuropeptide interactions in hypothalamus and amygdala related to social anxiety. Prog Brain Res 170:291-303

Churchland PS, Winkielman P (2012) Modulating social behavior with oxytocin: how does it work? What does it mean? Horm Behav 61(3):392-399

Crouch JL, Skowronski JJ, Milner JS et al (2008) Parental responses to infant crying: The influence of child physical abuse risk and hostile priming. Child Abuse and Neglect 32:702-710

De Dreu CKW, Greer LL, Handgraag MJ et al (2010) The neuropeptide oxytocin regulates parochial altruism in intergroup conflict among humans. Science 328(5984):1408-1411

De Geest K, Thiery M, Piron-Possuyt G et al (1985) Plasma oxytocin in human pregnancy and parturition. J Perinat Med 13(1):3-13

De Wolff MS, Van IJzendoorn M H (1997) Sensitivity and attachment: A meta-analysis on parental antecedents of infant attachment. Child dev 68(4):571-591

Denson TF, Mehta PH, Tan DH (2013) Endogenous testosterone and cortisol jointly influence reactive aggression in women. Psychoneuroendocrinology 38(3):416-424

Depue RA, Morrone-Strupinsky JV (2005) A neurobehavioral model of affiliative bonding: implications for conceptualizing a human trait of affiliation. Behav Brain Sci 28:313-350

Domes G, Heinrichs M, Glascher J et al (2007) Oxytocin attenuates amygdala responses to emotional faces regardless of valence. Biol Psychiatr 62:1187-1190

Domes G, Lischke A, Berger C et al (2010) Effects of intranasal oxytocin on emotional face processing in women. Psychoneuroendocrinology 35:83-93

Dykas MJ, Cassidy J (2011) Attachment and the processing of social information across the life span: theory and evidence. Psychol Bull 137(1):19

Elmadih A, Wan MW, Numan M et al (2014) Does oxytocin modulate variation in maternal caregiving in healthy new mothers? Brain Res 1580:143-150

Elwood RW, Mason C (1994) The couvade and the onset of paternal care: A biological perspective. Ethol Sociobiol 15(3):145-156

Fahrbach SE, Morrell JI, Pfaff DW (1984) Oxytocin induction of short-latency maternal behavior in nulliparous, estrogen-primed female rats. Horm Behav 18(3):267-286 
Fahrbach SE, Morrell JI, Pfaff DW (1985) Possible role for endogenous oxytocin in estrogen-facilitated maternal behavior in rats. Neuroendocrinology 40(6):526-532

Fearon RP, Bakermans-Kranenburg MJ, Van IJzendoorn MH et al (2010) The significance of insecure attachment and disorganization in the development of children's externalizing behavior: a meta-analytic study. Child Dev 81(2): 435-456

Feinman S (1980) Infant response to race, size, proximity, and movement of strangers. Inf Behav Dev 3:187-204

Feldman R, Bakermans-Kranenburg MJ (2017). Oxytocin: a parenting hormone. Current Opinion in Psychology 15:13-18

Feldman R, Gordon I, Schneiderman I et al (2010) Natural variations in maternal and paternal care are associated with systematic changes in oxytocin following parent-infant contact. Psychoneuroendocrinology 35(8):11331141

Feldman R, Weller A, Zagoory-Sharon O et al (2007) Evidence for a neuroendocrinological foundation of human affiliation plasma oxytocin levels across pregnancy and the postpartum period predict mother-infant bonding. Psych Sci 18:965-970

Fessler DMT (2002) Reproductive immunosuppression and diet: an evolutionary perspective on pregnancy sickness and meat consumption. Curr Anthropol 43:19-39

Flaxman SM, Sherman PW (2000) Morning sickness: a mechanism for protecting mother and embryo. Q Rev Biol 75:113-148

Fleming AS, Corter C, Stallings J et al (2002) Testosterone and prolactin are associated with emotional responses to infant cries in new fathers. Horm Behav 42:399-413

Fleming AS, Steiner M, Anderson V (1987) Hormonal and attitudinal correlates of maternal behavior during the early postpartum period. J Reprod Inf Psychol 5:193-205

Fleming AS, Steiner M, Corter C (1997) Cortisol, hedonics, and maternal responsiveness in human mothers. Horm Behav 32(2):85-98

Forbes S (2002) Pregnancy sickness and embryo quality. Trends Ecol Evol 7:115-120

Furneaux EC, Langley-Evans AJ, Langley-Evans SC (2001) Nausea and vomiting of pregnancy: endocrine basis and contribution to pregnancy outcome. Obstet Gynecol Surv 56:775-782

Galbally M, Lewis AJ, Van IJzendoorn MH et al (2011) The role of oxytocin in mother-infant relations: a systematic review of human studies. Harvard Rev Psychiat 19(1):1-14

Gettler LT, McDade TW, Agustin S et al (2013) Progesterone and estrogen responsiveness to father-toddler interaction. Am J Hum Biol 25(4):491-498

Gettler LT, McDade TW, Feranil AB et al (2011) Longitudinal evidence that fatherhood decreases testosterone in human males. Proc Nat Aca Sci 108:16194-16199

Gilbert R, Widom CS, Browne K et al (2009) Burden and consequences of child maltreatment in high-income countries. Lancet 373:68-81

Gilead M, Liberman N (2014) We take care of our own, caregiving salience increases out-group bias in response to out-group threat. Psychol Sci 25:1380-1387

Gimpl G, Fahrenholz F (2001) The oxytocin receptor system: structure, function, and regulation. Physiol Rev $81: 629-683$ 
Gordon I, Zagoory-Sharon O, Leckman JF et al (2010) Prolactin, oxytocin, and the development of paternal behavior across the first six months of fatherhood. Horm Behav 58(3):513-518

Gordon I, Zagoory-Sharon O, Schneiderman I et al (2008) Oxytocin and cortisol in romantically unattached young adults: associations with bonding and psychological distress. Psychophysiol 45(3):349-352

Groh AM, Fearon RP, Bakermans-Kranenburg MJ et al (2014) The significance of attachment security for children's social competence with peers: A meta-analytic study. Att Hum Dev 16(2):103-136

Groh AM, Roisman GI (2009) Adults' autonomic and subjective emotional responses to infant vocalizations: The role of secure base script knowledge. Dev Psychol 45(3):889

Groh AM, Roisman GI, Van IJzendoorn MH et al (2012) The significance of insecure and disorganized attachment for children's internalizing symptoms: A meta-analytic study. Child Dev 83(2):591-610

Grossmann K, Grossmann KE, Kindler H et al (2008) A wider view of attachment and exploration: the influence of mothers and fathers on the development of psychological security from infancy to young adulthood. In Cassidy J, Shaver PR (eds) Handbook of Attachment: Theory, Research, and Clinical Applications, Guilford Press, New York, p 857-879

Guastella AJ, MacLeod C (2012) A critical review of the influence of oxytocin nasal spray on social cognition in humans: evidence and future directions. Horm Behav 61(3): 410-418

Hahn-Holbrook J, Holbrook C, Bering J (2010) Snakes, spiders, strangers: how the evolved fear of strangers may misdirect efforts to protect children from harm. In: Lampinen JM, Sexton-Radek K (eds) Protecting Children from Violence: Evidence Based Interventions. Psychology Press, New York, p 263-289

Hahn-Holbrook J, Holbrook C, Hasselton MG (2011) Parental precaution: Neurobiological means and adaptive ends. Neurosci Biobehav Rev 35:1052-1066

Hahn-Holbrook J, Holt-Lunstad J, Holbrook C et al (2011) Maternal defense: Breast feeding increases aggression by reducing stress. Psychol Sci 22:1288-1295

Heinrichs M, Domes G (2008) Neuropeptides and social behavior: Effects of oxytocin and vasopressin in humans. Prog Brain Res 170:337-350

Heinrichs M, Meinlschmidt G, Neumann I et al (2001) Effects of suckling on hypothalamic-pituitary-adrenal axis responses to psychosocial stress in postpartum lactating women. J Clinic Endocrinol Metabol 86(10):47984804

Hill K, Hurtado AM (1996) Ache life history: The ecology and demography of a foraging people. Aldine de Gruyter, New York

Hrdy SB (1999) Mother nature: a history of mothers, infants and natural selection. Pantheon, New York

Hrdy SB (2011) Mothers and others: The evolutionary origins of mutual understanding. Harvard University Press

Hurtado AM, Hill K (1992) Parental effect on offspring survivorship among Ache and Hiwi hunter-gathers: implication for modeling pair-bonding stability. In: Hewlett B (ed) Father-Child Relations: Cultural and Biosocial Contexts. Aldine de Gruyter, New York

Insel TR (2010) The challenge of translation in social neuroscience: a review of oxytocin, vasopressin, and affiliative behavior. Neuron 65(6):768-779

Insel TR, Young LJ (2001) The neurobiology of attachment. Nat Rev Neurosci 2:129-136 
Jones B, Perrett D, Little A et al (2005) Menstrual cycle, pregnancy and oral contraceptive use alter attraction to apparent health in faces. P R Soc Lond B Bio 272:347-354

Kagerbauer SM, Martin J, Schuster T et al (2013) Plasma oxytocin and vasopressin do not predict neuropeptide concentrations in the human cerebrospinal fluid. J Neuroendocrinol 25:668-673

Kantrowitz B (1997) Off to a good start. Newsweek 7(129):6-9

Kavaliers M, Choleris E, Ågmo A et al (2004) Olfactory-mediated parasite recognition and avoidance: Linking genes to behavior. Horm Behav 46:272-283

Kendrick KM (2000) Oxytocin, motherhood and bonding. Exp Physiol 85:111s-124s

Kendrick KM, Da Costa AP, Broad KD et al (1997) Neural control of maternal behaviour and olfactory recognition of offspring. Brain Res Bull 44(4):383-395

Keverne EB, Kendrick KM (1992) Oxytocin facilitation of maternal behavior in sheep. Ann New York Aca Sci 652:83-101

Kidscape (1993) How safe are our children? London: Kidscape

Kim P, Feldman R, Mayes LC et al (2011) Breastfeeding, brain activation to own infant cry, and maternal sensitivity. J Child Psychol Psychiatry 52:907-915

Kringelbach ML (2005) The human orbitofrontal cortex: linking reward to hedonic experience. Nat Rev Neurosci 6(9):691-702

Kringelbach ML, Lehtonen A, Squire S et al (2008) A specific and rapid neural signature for parental instinct. PLoS One, 3(2):e1664

Kumsta R, Hummel E, Chen FS et al (2013) Epigenetic regulation of the oxytocin receptor gene: implications for behavioral neuroscience. Front Neurosci 7(83):1-6

Lamb ME, Hwang CP, Frodi AM et al (1982) Security of mother-and father-infant attachment and its relation to sociability with strangers in traditional and nontraditional Swedish families. Inf Behav Dev 5(2):355-367

Lane A, Luminet O, Nave G et al (2016) Is there a publication bias in behavioral intranasal oxytocin research on humans? Opening the file drawer of one lab. J Neuroendocrinol: Molecular Translat Neurobiol 28(4):2-15

Leckman JF, Mayes LC, Feldman R et al (1999) Early parental preoccupations and behaviors and their possible relationship to the symptoms of obsessive-compulsive disorder. Acta Psychiatr Scand Suppl 396:1-26

LeDoux JE (2000) Emotion circuits in the brain. Ann Rev Neurosci 23:155-184

Leerkes EM, Blankson AN, O'Brien M (2009) Differential effects of maternal sensitivity to infant distress and non-distress on social-emotional functioning. Child Dev 80(3):762-775

Leerkes EM, Siepak KJ (2006) Attachment linked predictors of women's emotional and cognitive responses to infant distress. Att Hum Dev 8(1):11-32

Leger DW, Thompson RA, Merritt JA et al (1996) Adult perception of emotion intensity in human infant cries: Effects of infant age and cry acoustics. Child Dev 67(6):3238-3249

Leitman DI, Wolf DH, Ragland JD et al (2010) "It's not what you say, but how you say it": a reciprocal temporofrontal network for affective prosody. Front Hum Neurosci 4:19

Macgregor DM (2003) Accident and emergency attendances by children under the age of 1 year as a result of injury. Emerg Med J 20:21-24 
Maclean PD (1990) The triune brain in evolution. Role of paleocerebral functions. Plenum Press, New York

Mah BL (2016) Oxytocin, postnatal depression, and parenting: A systematic review. Harvard Rev Psychiatry 24(1):1-13

Mah BL, Bakermans-Kranenburg MJ, Van IJzendoorn MH et al (2014) Oxytocin promotes protective behavior in depressed mothers: a pilot study with the enthusiastic stranger paradigm. Depression and Anxiety 32(2):76-91

McElwain NL, Booth-LaForce C (2006) Maternal sensitivity to infant distress and non-distress as predictors of infant-mother attachment security. J Fam Psychol 20:247-255

Mehta PH, Josephs RA (2010) Testosterone and cortisol jointly regulate dominance: Evidence for a dualhormone hypothesis. Horm Behav 58(5): 898-906

Mendes D, Seidl-de-Moura ML, Siqueira JD (2009) The ontogenesis of smiling and its association with mothers' affective behaviors: a longitudinal study. Infant Behav Dev 32: 445-453

Mezzacappa ES (2004) Breastfeeding and maternal stress response and health. Nutrition Rev 67:261-268

Mizugaki S, Maehara Y, Okanoya K et al (2015) The Power of an Infant's Smile: Maternal Physiological Responses to Infant Emotional Expressions. PLoS ONE 10(6):e0129672

Naber FBA, Poslawsky IE, Van IJzendoorn MH et al (2012) Brief report: oxytocin enhances paternal sensitivity to a child with autism: a double-blind within-subject experiment with intranasally administered oxytocin. J Autism Dev Disorders 43:224-229

Naber FBA, Van IJzendoorn MH, Deschamps P et al (2010) Intranasal oxytocin increases fathers' observed responsiveness during play with their children: a double-blind within-subject experiment. Psychoneuroendocrinology 35:1583-1586

Navarrete CD, Olsson A, Ho AK et al (2009) Fear extinction to an out-group face the role of target gender. Psychol Sci 20(2):155-158

Neumann ID, Slattery DA (2016) Oxytocin in general anxiety and social fear: A translational approach. Biol Psychiat 79(3):213-221

Nishimori K, Young LJ, Guo Q et al (1996) Oxytocin is required for nursing but is not essential for parturition or reproductive behavior. Proc Nat Aca Sci 93(21):11699-11704

Olff M, Frijling JL, Kubzansky LD et al (2013) The role of oxytocin in social bonding, stress regulation and mental health: An update on the moderating effects of context and interindividual differences Psychoneuroendocrinology 38(9):1883-1894

Ostrowski NL (1998) Oxytocin receptor mRNA expression in rat brain: implications for behavioral integration and reproductive success. Psychoneuroendocrinology 23:989-1004

Otali E, Gilchrist JS (2006) Why chimpanzee (Pan troglodytes schweinfurthii) mothers are less gregarious than nonmothers and males: the infant safety hypothesis. Behav Ecol Sociobio 59:561-570

Paquette D (2004) Theorizing the father-child relationship: Mechanisms and developmental outcomes. Hum Dev 47(4):193-219

Pedersen CA, Ascher JA, Monroe YL et al (1982) Oxytocin induces maternal behavior in virgin female rats. Science 216(4546): 648-650

Pedersen CA, Caldwell JD, Walker C et al (1994) Oxytocin activates the postpartum onset of rat maternal behavior in the ventral tegmental and medial preoptic areas. Behav neurosci 108(6):1163 
Pepper GV, Roberts SC (2006) Rates of nausea and vomiting in pregnancy and dietary characteristics across populations. P Roy Soc B-Biol Sci 273:2675-2679

Quintana DS, Guastella AJ, Westlye LT et al (2016) The promise and pitfalls of intranasally administering psychopharmacological agents for the treatment of psychiatric disorders. Mol Psychiat 21(1):29-38

Reijman S, Alink LRA, Compier-de Block LH et al (2014) Autonomic reactivity to infant crying in maltreating mothers. Child Maltreat 19:101-112

Reijman S, Alink LRA, Compier-de Block LH et al (2015) Salivary $\alpha$-Amylase Reactivity to Infant Crying in Maltreating Mothers. Child Psychiat Hum Dev 46(4):589-599

Reijneveld SA, Van der Wal MF, Brugman E et al (2004) Infant crying and child abuse. Lancet 364:1340-1342

Riem MME, Bakermans-Kranenburg MJ, Pieper S et al (2011) Oxytocin modulates amygdala, insula, and inferior frontal gyrus responses to infant crying: a randomized controlled trial. Biol Psychiatry 70:291-297

Riem MME, Bakermans-Kranenburg MJ, Van IJzendoorn MH (2016) Intranasal administration of oxytocin modulates behavioral and amygdala responses to infant crying in females with insecure attachment representations. Att Hum Dev 18(3):213-234

Riem MME, Bakermans-Kranenburg MJ, Van IJzendoorn MH et al (2012) Attachment in the brain: adult attachment representations predict amygdala and behavioral responses to infant crying. Att Hum Dev 14:533551

Riem MME, Van IJzendoorn MH, Tops M et al (2012) No laughing matter: Intranasal oxytocin administration changes functional brain connectivity during exposure to infant laughter. Neuropsychopharmacology 37:12571266

Riem MME, Voorthuis A, Bakermans-Kranenburg MJ et al (2014) Pity or peanuts? Oxytocin induces different neural responses to the same infant crying labeled as sick or bored. Dev Sci 17:248-256

Righetti-Veltema M, Conne-Perreard E, Bousquet A et al (2002) Postpartum depression and mother-infant relationship at 3 months old. J Aff Dis 70(3):291-306

Rilling JK (2013) The neural and hormonal bases of human parental care. Neuropsychologia 51:731-747

Rimmele U, Hediger K, Heinrichs M et al (2009) Oxytocin makes a face in memory familiar. J

Neurosci 29(1):38-42

Rocchetti M, Radua J, Paloyelis Y et al (2014) Neurofunctional maps of the 'maternal brain' and the effects of oxytocin: A multimodal voxel-based meta-analysis. Psychiatry and clinical neurosciences 68(10):733-751

Sadedin S (2014) War in the womb. In: Aeon. Available via Aeon: https://aeon.co/essays/why-pregnancy-is-abiological-war-between-mother-and-baby. Accessed 5 May 2016

Simpson JA, Belsky J (2008) Attachment theory within a modern evolutionary framework: Theory, research, and clinical applications. In: Cassidy J, Shaver PR (eds) Handbook of attachment: Theory, research, and clinical applications, 2nd edn. Guilford, New York, p 131-157

Skarin K (1977) Cognitive and contextual determinants of stranger fear in six-and eleven-month-old infants. Child Dev 48:537-544

Sroufe LA, Waters E (1976) The ontogenesis of smiling and laughter: A perspective on the organization of development in infancy. Psychol Rev 83(3):173 
Stallings J, Fleming AS, Corter C et al (2001) The effects of infant cries and odors on sympathy, cortisol, and autonomic responses in new mothers and nonpostpartum women. Parenting 1(1-2):71-100

Storey AE, Walsh CJ, Quinton RL et al (2000) Hormonal correlates of paternal responsiveness in new and expectant fathers. Evol Hum Behav 21:79-95

Strathearn L, Fonagy P, Amico J et al (2009) Adult attachment predicts maternal brain and oxytocin response to infant cues. Neuropsychopharmacology 34:2655-2666

Stribley JM, Carter CS (1999) Developmental exposure to vasopressin increases aggression in adult prairie voles. Proc Natl Acad Sci USA 96:12601-04

Striepens N, Scheele D, Kendrick KM et al (2012) Oxytocin facilitates protective responses to aversive social stimuli in males. Proc Nat Aca Sci 109(44)18144-18149

Swain JE (2008) Baby stimuli and the parent brain: functional neuroimaging of the neural substrates of parentinfant attachment. Psychiatry 5:28-36

Swain JE, Kim P, Spicer J et al (2014) Approaching the biology of human parental attachment: Brain imaging, oxytocin and coordinated assessments of mothers and fathers. Brain Research 1580:78:101

Takayanagi Y, Yoshida M, Bielsky IF et al (2005) Pervasive social deficits, but normal parturition, in oxytocin receptor-deficient mice. Proc Nat Aca Sci USA 102(44):16096-16101

Taylor SE (2002) The tending instinct: How nurturing is essential to who we are and how we live. Holt, New York

Taylor SE, Klein LC, Lewis BP (2000) Biobehavioral responses to stress in females: tend-and-befriend, not fight-or-flight. Pscychol Rev 107:411-429

Theodoridou A, Penton-Voak IS, Rowe AC (2013) A direct examination of the effect of intranasal administration of oxytocin on approach-avoidance motor responses to emotional stimuli. Plos One 8(2):e58113

Thompson RR, George K, Walton JC et al (2006) Sex-specific influences of vasopressin on human social communication. Proc Natl Acad Sci USA 103(20):7889-7894

UNICEF (2013) Levels \& Trends in Child Mortality, IGME Report 2013

Van Anders SM, Tolman RM, Volling BL (2012) Baby cries and nurturance affect testosterone in men. Horm Behav 61(1):31-36

Van Hooff JA (1972) A comparative approach to the phylogeny of laughter and smiling. In: Hinde RA (ed) Nonverbal communication, University Presss, Cambridge, p 209-241

Van IJzendoorn MH, Bakermans-Kranenburg MJ (2012) A sniff of trust: meta-analysis of the effects of intranasal oxytocin administration on face recognition, trust to in-group, and trust to out-group.

Psychoneuroendocrinology 37:438-443

Van IJzendoorn MH, Bakermans-Kranenburg MJ (2016) The role of oxytocin in parenting and as augmentative pharmacotherapy; critical issues and bold conjectures. J Neuroendocrinology 28

Viau V (2002) Functional cross-talk between the hypothalamic-pituitary-gonadal and-adrenal axes. J Neuroendocrinology 14(6):506-513

Voorthuis A, Riem MME, Van IJzendoorn MH et al (2014) Reading the mind in the infant eyes: Paradoxical effects of oxytocin on neural activity and emotion recognition in watching pictures of infant faces. Brain Research 1580:151-159 
Weissman O, Zagoory-Sharon O, Feldman R (2014) Oxytocin administration, salivary testosterone, and fatherinfant social behavior. Progr Neuro-Psychopharmacol Biol Psychiat 49:47-52

Williams LM, Kemp AH, Felmingham K et al (2006) Trauma modulates amygdala and medial prefrontal responses to consciously attended fear. Neuroimage 29:347-357

Wood RM, Gustafson GE (2001) Infant crying and adults' anticipated caregiving responses: Acoustic and contextual influences. Child Dev 72(5):1287-1300

Woody EZ, Szechtman H (2011) Adaptation to potential threat: the evolution, neurobiology, and psychopathology of the security motivation system. Neurosci Biobehav Rev 35:1019-1033

Wright ND, Bahrami B, Johnson E et al (2012) Testosterone disrupts human collaboration by increasing egocentric choices. Proc Biol Sci 279:2275-2280

Wynne-Edwards KE, Reburn CJ (2000) Behavioral endocrinology of mammalian fatherhood. Trends Ecol Evol 15:464-468

Young LJ, Winslow JT, Wang Z et al (1997) Gene targeting approaches to neuroendocrinology: oxytocin, maternal behavior, and affiliation. Horm Behav 31(3):221-231

Zilioli S, Ponzi D, Henry A et al (2014) Testosterone, Cortisol and Empathy: Evidence for the Dual-Hormone Hypothesis. Adapt Hum Behav Physiol 1(4):421-433 